\title{
Polyoxometalate entrapped caprolactam gels and their cytotoxicity study
}

\author{
K SHAKEELA ${ }^{\mathrm{a}}$, G SILPA ${ }^{\mathrm{b}}$, SURESH KUMAR RAYALA ${ }^{\mathrm{b}}$ and G RANGA RAO ${ }^{\mathrm{a}, *}$ \\ a Department of Chemistry, Indian Institute of Technology Madras, Chennai 600 036, Tamilnadu, India \\ ${ }^{b}$ Bhupat and Jyoti Mehta School of Biosciences, Indian Institute of Technology Madras, Chennai 600 036, \\ Tamilnadu, India \\ E-mail: grrao@iitm.ac.in
}

MS received 26 April 2018; accepted 18 May 2018; published online 27 July 2018

\begin{abstract}
Polyoxometalate (POM) based gels are synthesized by reacting POMs with an excess of caprolactam. These POM-entrapped caprolactam gels are thermoreversible and possess good mechanical strength. The gelation of POMs in caprolactam matrix brought the gel acidity similar to the physiological $\mathrm{pH}$. The cytotoxicity studies on SCC 131 cell lines using these gels show $50 \%$ of cell death in the range of 2 to $6 \mathrm{mM}$ concentration in $48 \mathrm{~h}$. The supramolecular caprolactam matrix with active protons and the redox property of POMs are responsible for the cytotoxicity effect.
\end{abstract}

Keywords. Polyoxometalates; caprolactam; gels; cytotoxicity.

\section{Introduction}

Polyoxometalates (POMs) are nanosized metal-oxide clusters, which have diverse applications in the fields like, medicine, magnetism, optics and catalysis. ${ }^{1}$ The properties and applications of POMs can be enhanced many folds by modification or functionalization of POM units. POMs can be covalently functionalized with desired organic groups or modified by protonic exchange with organic cations producing novel POMbased hybrid materials. ${ }^{2-5}$ These hybrid materials are best used in the field of heterogeneous catalysis. ${ }^{6,7}$ POMs can form soft gel type materials. ${ }^{8-13}$ For instance, the self-assembly of a polyoxomolybdate cluster and $\left[\mathrm{PdCl}_{2}(\mathrm{PhCN})_{2}\right]$ produced a birefringent gel, with the anisotropic arrangement of ions in the material. ${ }^{8}$ Recently, poly(urethane amide) modified Anderson type POM-based gelator showed self-assembly to form high-ordered single molecular layer ribbons. ${ }^{9}$ Later, a supramolecular POM gel made up of nano-rolls containing polymerized butanone and esters, self-assembled with Dawson-type POMs was reported. ${ }^{10}$ In this regard, it is important to note that the POMs can form polyoxometalate-based ionic liquids with long chain quaternary ammonium and phosphonium ions. Vanadium-substituted POMs have formed gel-type materials with pyridinium-based ions. This series of

\footnotetext{
*For correspondence
}

gels are thermo-reversible and conductive. Hence, they are used as gel electrolytes. ${ }^{11,12}$ POMs are also seen to get encapsulated in a self-assembled carboxy-methylchitosan hydrogel, which has physiological $\mathrm{pH} .{ }^{13}$ Such gels can be expected to show biological activity. The reason for the softness of these materials is that the long chains present in the cationic moiety increase the dspacing.

The POMs are known to exhibit anticancer, antibacterial and antiviral properties. For instance, Keggin-type silicotungstate modified with pipemedic acid $\left\{\left[\mathrm{Co}(\mathrm{PPA})_{2}\right] \mathrm{H}_{2}\left[\mathrm{SiW}_{12} \mathrm{O}_{40}\right]\right\} \cdot \mathrm{HPPA} \cdot 3 \mathrm{H}_{2} \mathrm{O}$, showed antitumoral activity towards MCF-7 cells. ${ }^{14}$ Similarly, tri-organic-tin-substituted germanotungstate showed an anticancer effect in hepatocarcinoma $\mathrm{H} 22$ mice cell lines. ${ }^{15}$ The highly negative charged POMs like $\mathrm{As}_{4} \mathrm{~W}_{40}$, $\mathrm{Sb}_{9} \mathrm{~W}_{21}$ and the Keggin-type $\mathrm{K}_{5}\left[\mathrm{SiVW}_{11} \mathrm{O}_{40}\right]$ showed bacteriocidal and bacteriostatic activity on Helicobacter pyroli cells. ${ }^{16}$ However, the instability of POMs in water at physiological $\mathrm{pH}$, strong acidity and toxicity of POMs is impeding their clinical use from several years. This led to a multidisciplinary challenge. Hence, several methods are being developed to overcome such undesirable effects of POMs. There are some limited reports, in which POMs have been encapsulated in some polymer matrix in order to reduce toxicity and improve biological activity. ${ }^{17-19}$ So far, biopolymers like chitosan and starch are used for encapsulation and nano 
carriers of POMs. ${ }^{20-24}$ In a recent study by Rejinold et al., a thermoresponsive polymer, chitosan-g-poly $(\mathrm{N}-$ vinylcaprolactam) is used for cancer drug delivery. ${ }^{25,26}$ In another report, amino caprolactam derivatives were shown to exhibit $\lambda$-secretase inhibitors which can be a potent drug for Alzheimer's disease. ${ }^{27}$

In our earlier report, Keggin-based POMs, such as phosphotungstic acid and phosphomolybdic acid produced hybrid salts with $\varepsilon$-caprolactam (CL). ${ }^{28}$ As a continuation to our work, we have tried to entrap POMs in caprolactam matrix. Here, we have increased the spacing between the Keggin units by increasing caprolactam concentration. The resultant gel materials are characterized and tested for POM cytotoxicity towards SCC131 cancer cell lines in dose and time-dependent manner and the results are reported here.

\section{Experimental}

\subsection{Synthesis of POM-based gels}

The Keggin-type POMs used in the present work are phosphotungstic acid, $\mathrm{H}_{3} \mathrm{PW}_{12} \mathrm{O}_{40}$ (PWA) and phosphomolybdic acid, $\mathrm{H}_{3} \mathrm{PMo}_{12} \mathrm{O}_{40}(\mathrm{PMoA})$. Both the POMs were purchased from Fisher Scientific, Mumbai and $\varepsilon$-caprolactam from Aldrich Chemicals, Bengaluru. The chemicals were of analytical grade and used as received. Equal volumes of POM and caprolactam solutions (about 1:60 mole ratio) were mixed, which resulted in immediate precipitation, as in the case of hybrids reported in our earlier work, as shown in Figure $1(\mathrm{I}) \mathrm{c}^{28}$ The reaction mixtures were kept in the oven at $60^{\circ} \mathrm{C}$, so as to slowly evaporate the water. As water molecules
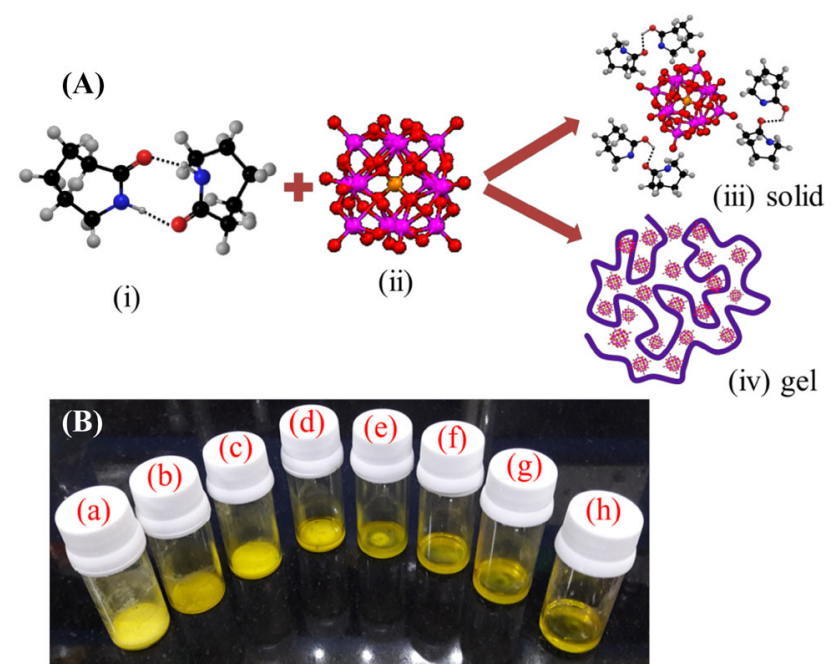

Figure 1. (A) Reaction scheme representing caprolactam dimer (i), on reaction with POM (ii), producing hybrid salt (iii) and gel (iv); (B) solid to gel transition from (a) to (h) when 1 mole of PMoA reacted with 6, 10, 20, 30, 40, 50, 55 and 60 moles of caprolactam, respectively. escaped, the precipitate was broken down and a clear viscous liquid was formed shown in Figure 1A(iv). The amount of POM to caprolactam in terms of mole ratio has been optimized and shown in Figure 1B. Viscous liquid formation was observed from 1:30 (POM:CL) mole ratio (Figure 1B(d)). But complete transformation of precipitate to clear liquid state was achieved only at 1:60 POM:CL mole ratio. On cooling this liquid to room temperature, it formed a homogeneous gel-like material, as depicted in Figure 1A(iv). The gels formed with PWA and PMoA were named as CLPW-gel and CLPMo-gel, respectively.

\subsection{Characterization}

The JASCO FT-IR-4100 spectrophotometer was used to record FTIR spectra of the starting materials and gels by $\mathrm{KBr}$ pellet method at room temperature. Thermogravimetric analyses (TGA) of the samples were performed on TA make TGA (Perkin-Elmer) Q500 instrument under nitrogen flow at a linear heating rate of $10^{\circ} \mathrm{C}$ per minute, from room temperature to $900^{\circ} \mathrm{C}$. The phase transitions of the gels were tested on a TA make DSC (Perkin-Elmer) Q200. Rheological measurements were carried out for the gels using a stress-controlled rheometer ANTON PAAR, Physica 301, Germany, having cone-plate geometry of $25 \mathrm{~mm}$ diameter with a cone angle $2^{\circ}$. The measurements were carried out with a gap size of $1 \mathrm{~mm}$ at $25^{\circ} \mathrm{C}$, over a shear rate of 0.1 to $100 \mathrm{~s}^{-1}$.

\subsection{Cytotoxicity assay}

The MTT (3-(4,5-Dimethylthiazol-2-yl)-2,5-diphenyltetrazolium bromide) is a modified colorimetric assay which measures the capability of viable cells to reduce yellow tetrazolium salt to soluble purple formazan product by mitochondrial reductases. Briefly, $5 \times 10^{3}$ cells for SCC131 were seeded equally using DMEM-HG (Dulbecco's modified Eagle's medium - high glucose) containing 10\% FBS (foetal bovine serum), into 96-well plates as triplicates. $1 \mathrm{M}$ stock solution was made for the gels and their solubility at different concentrations was tested in the cell culture growth media. It was observed that the viscosity is retained in the media at concentrations higher than $100 \mathrm{mM}$. Taking this concentration as the maximum, the cytotoxicity was evaluated at different concentrations lower to $100 \mathrm{mM}$. Cells at log phase were treated with POM-based gels at 2-20 mM concentration range for a period of 24,48 and $72 \mathrm{~h}$. After each treatment period, $10 \mu \mathrm{L}$ of $5 \mathrm{mg} / \mathrm{mL}$ MTT solution in PBS was added to each well and incubated at $37^{\circ} \mathrm{C}$ for $4 \mathrm{~h}$, and the formazan crystals in each well were dissolved in $100 \mu \mathrm{L}$ of dimethylsulphoxide. Absorbance was measured at $570 \mathrm{~nm}$ with $650 \mathrm{~nm}$ as background using Spectramax M5 plate reader.

The cell viability was calculated using Absorbance (A) by the formula:

$$
\begin{aligned}
& \% \text { Cell viability } \\
& =\frac{\text { Absorbance (Avg. of triplicate sample values) }}{\text { Absorbance (Avg. of triplicate control values) }} \times 100
\end{aligned}
$$




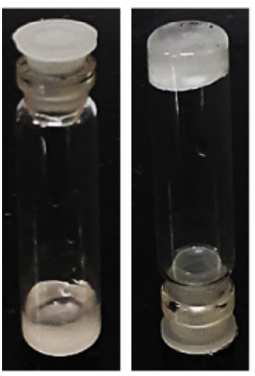

(a)

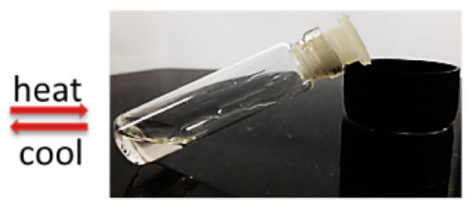

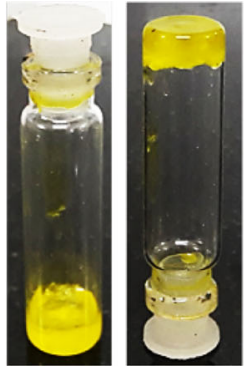

(b)

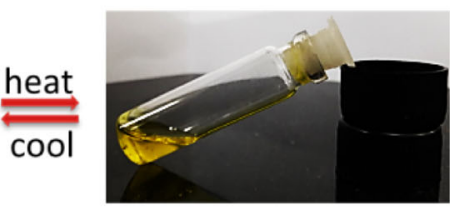

Figure 2. Gels showing thermoreversibility when heated to $60^{\circ} \mathrm{C}$ and cooled to room temperature: (a) CLPW-gel and (b) CLPMo-gel.

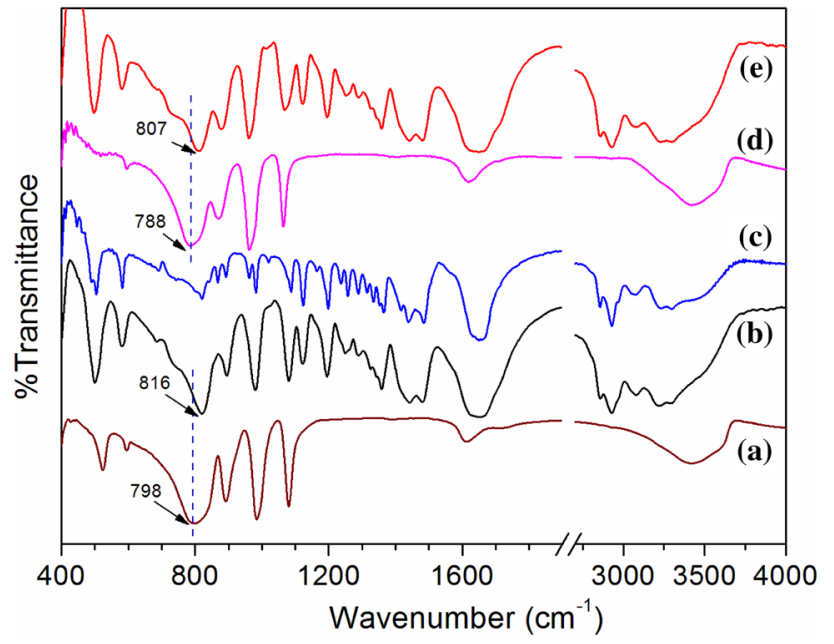

Figure 3. FTIR spectra of (a) PWA, (b) CLPW-gel, (c) caprolactam, (d) PMoA and (e) CLPMo-gel.

\section{Results and Discussion}

The POM-caprolactam hybrid salts, reported earlier, ${ }^{28}$ are solid and hydrophobic. But the gels reported here are soft and highly hydrophilic. These gels are thermoreversible, as they become clear viscous liquids on heating to $60^{\circ} \mathrm{C}$ and gelled again on cooling to room temperature, shown in Figure 2.

The high content of caprolactam in gels is well witnessed by the presence of prominent peaks corresponding to caprolactam in FTIR spectra, shown in Figure 3. However, the Keggin signature peaks are also seen clearly. The prominent peak at 798 and $788 \mathrm{~cm}^{-1}$ (Figures 3a, 3d) attributed to $\nu\left(\mathrm{M}-\mathrm{O}_{\mathrm{e}}-\mathrm{M}\right)$ in PWA and PMoA is blue shifted to 816 and $807 \mathrm{~cm}^{-1}$ (Figures $3 \mathrm{~b}, 3 \mathrm{e})$, respectively, in their corresponding gels. The shift can be interpreted as the edge-sharing oxygens in Keggin moiety are interacting with the caprolactam. However, the other peak values corresponding to Keggin vibrations are found unchanged. The caprolactam finger print region is still clearly noticed in the range of $1122-1780 \mathrm{~cm}^{-1}$ and the stretching vibrations of $\mathrm{C}-\mathrm{H}$ and $\mathrm{N}-\mathrm{H}$ bonds in caprolactam in the range of 2800 $3330 \mathrm{~cm}^{-1}$. The unchanged peak values in the gels, due to the caprolactam moieties, are attributed to the presence of a dominant quantity of caprolactam in both the gels.

The thermal behaviors of CLPW-gel and CLPMogel are shown in Figure 4. Both gels show single step decomposition in Figure 4A ( $a$ and $b$ ), which is similar to pure caprolactam in Figure 4A (c). The gels show slightly increased thermal stability because of the homogeneous distribution of Keggin ions in caprolactam matrix and equal interaction of Keggin with all caprolactam units. Further, the gels are analyzed by DSC, which show a single sharp endothermic peak at $61.7^{\circ} \mathrm{C}$ for CLPW-gel and $57.3^{\circ} \mathrm{C}$ for CLPMo-gel, corresponding to the melting points of the gels, is shown in Figure 4B.

The viscoelastic and dynamic properties of the gels are studied by rheological measurements. Figure 5 shows the frequency dependent rheological study of the gels which display that the storage modulus $\left(\mathrm{G}^{\prime}\right)$ is higher than the loss modulus $\left(\mathrm{G}^{\prime \prime}\right)$ throughout the sweep. This indicates that the gels show solid like behavior under the applied strain of $0.8 \%$ and the $\mathrm{G}$ / and $\mathrm{G}^{\prime \prime}$ are far apart without crossover point. Both the gels have a good mechanical strength of the order of $10^{5} \mathrm{~Pa}$ and the CLPW-gel has higher mechanical strength compared to CLPMo-gel. The dominant elastic behavior over viscous nature of these gels is an important property to be potential biomaterials. ${ }^{29}$

\subsection{Application of POM-CL gels for cytotoxic studies on SCC131 cell lines}

POMs are strongly acidic but their acidity approaches to physiological $\mathrm{pH}$ (6.9 to 7.1) after gelation with nontoxic supramolecular caprolactam matrix. This prompted us to study the cytotoxic effect of these gels. The in vitro screening for anti-cancer effect on head and neck cancer cell lines, SCC131, by POM-based gels was analyzed. The cytotoxicity of these gels was evaluated by 

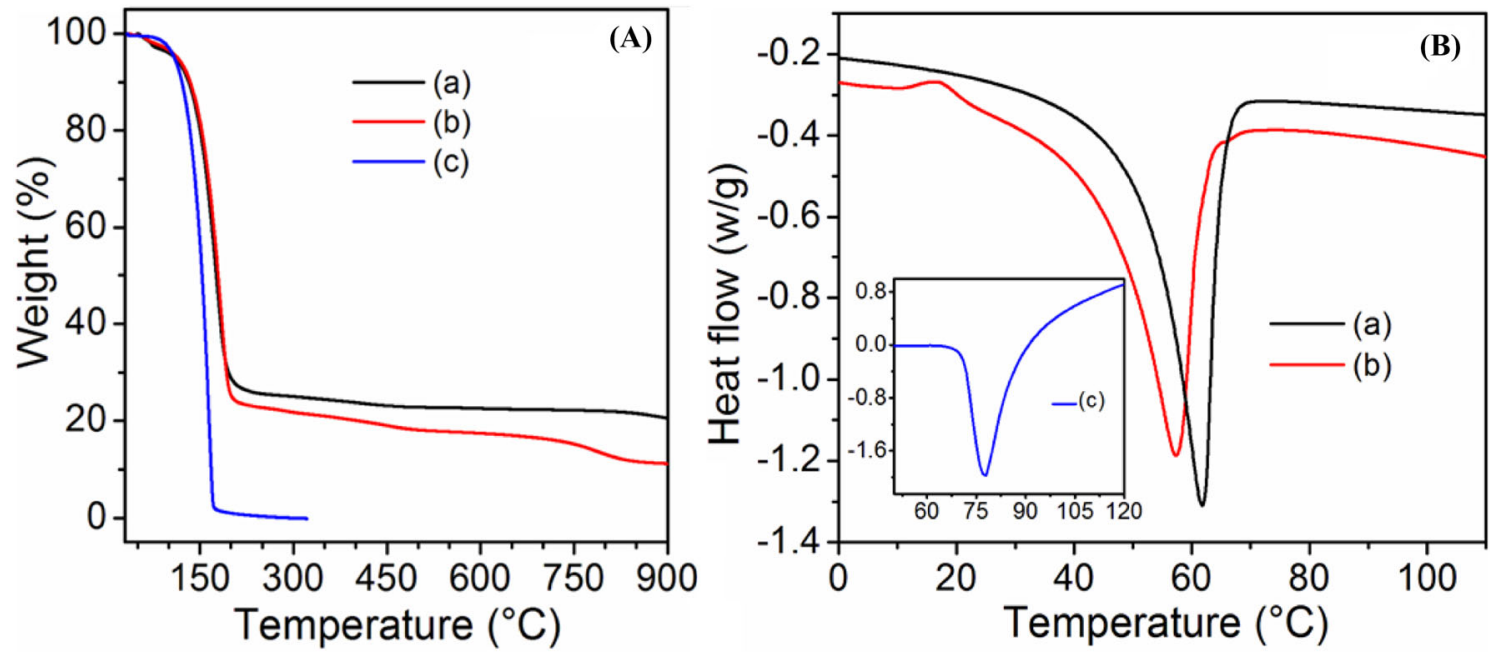

Figure 4. (A) Thermogravimetric analysis and (B) differential scanning calorimetry of (a) CLPW-gel, (b) CLPMo-gel and (c) caprolactam.
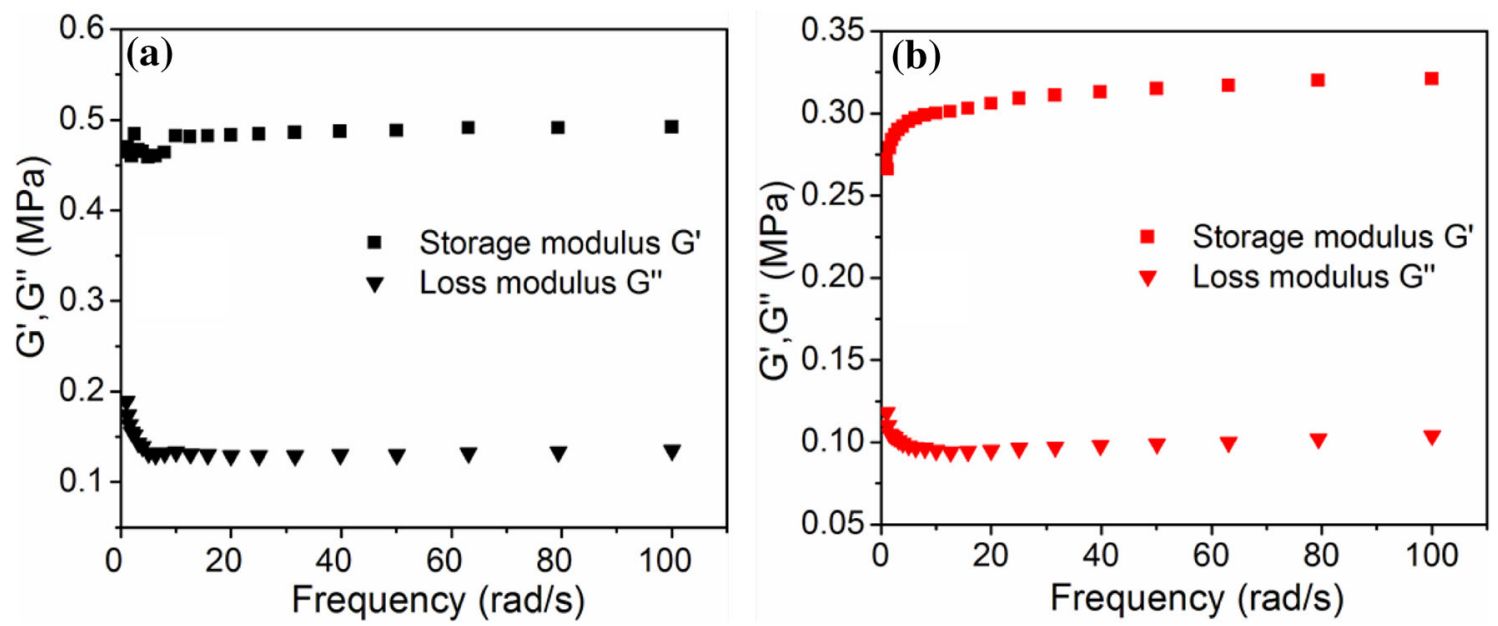

Figure 5. Rheological studies of (a) CLPW-gel and (b) CLPMo-gel, at an applied strain of $0.8 \%$.
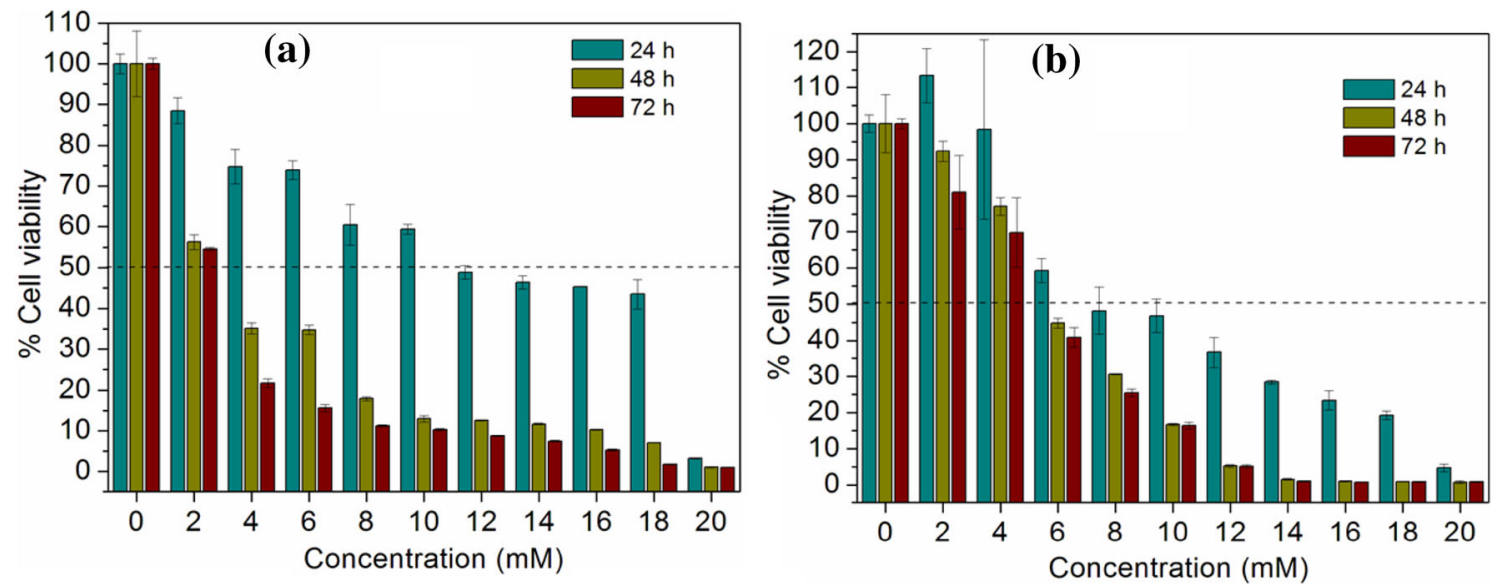

Figure 6. Effect of POM-based gels on the viability of SCC131 cell lines. Cells were treated with indicated concentrations of (a) CLPW-gel and (b) CLPMo-gel. The cytotoxic effect was determined by MTT assay. Each value represents mean $\pm \mathrm{SE}$. 
MTT assay and the results are shown in Figure 6. Cytotoxicity was observed in $24 \mathrm{~h}$ for both the gels. The CLPW-gel showed cytotoxicity in $24 \mathrm{~h}$, while CLPMogel showed cytotoxicity with a minimum concentration of $6 \mathrm{mM}$ for the same duration. However, the IC50 values for CLPW-gel and CLPMo-gel ranged between 2-4 $\mathrm{mM}$ and 4-6 $\mathrm{mM}$, respectively, at $48 \mathrm{~h}$ time point.

The mechanism of cytotoxicity by POMs involves destructive interaction with cell membranes. ${ }^{30}$ The protons of PWA and PMoA, involved in the hydrogen bonding in caprolactam, are possibly interacting with the negatively charged cell membranes leading to the discharge of intracellular components and subsequent cell death. Besides, both POMs are redox active and can oxidize the cell membrane, inhibiting rapid uncontrollable cell multiplicity. ${ }^{31}$ However, the exact mechanism of action and drug metabolism is being determined.

\section{Conclusions}

The transformation of caprolactam-POM hybrid salt to gel is demonstrated by gradually increasing the caprolactam to POM mole ratio. The gels show thermoreversibility. The $\nu\left(\mathrm{M}-\mathrm{O}_{\mathrm{e}}-\mathrm{M}\right)$ stretching is blue shifted by about $18 \mathrm{~cm}^{-1}$ revealing the interaction between the Keggin units and caprolactam matrix. The $\mathrm{pH}$ of these gels is similar to physiological $\mathrm{pH}$ which allowed us to study the cytotoxicity effect on SCC 131 head and neck cancer cell lines. Cytotoxicity was observed in as early as $24 \mathrm{~h}$ for both the gels. The IC50 values for CLPW-gel and CLPMo-gel at $72 \mathrm{~h}$ time point ranged between 2-4 $\mathrm{mM}$ and $4-6 \mathrm{mM}$, respectively.

\section{Acknowledgements}

Mrs. Shakeela would like to thank CSIR, New Delhi, for awarding JRF and SRF fellowships.

\section{References}

1. Long D, Tsunashima R and Cronin L 2010 Polyoxometalates: Building blocks for functional nanoscale systems Angew. Chem. Int. Ed. 491736

2. Dolbecq A, Dumas E, Mayer C R and Mialane P 2010 Hybrid organic-inorganic polyoxometalate compounds: From structural diversity to applications Chem. Rev. 110 6009

3. Proust A, Matt B, Villanneau R, Guillemot G, Gouzerha P and Izzeta G 2012 Functionalization and postfunctionalization: a step towards polyoxometalate-based materials Chem. Soc. Rev. 417605

4. Rajkumar T and Ranga Rao G 2008 Investigation of hybrid molecular material prepared by ionic liquid and polyoxometalate anion J. Chem. Sci. 120587
5. Rafiee E and Eavani S 2016 Heterogenization of heteropoly compounds: a review of their structure and synthesis $R S C A d v .646433$

6. Pathan S and Patel A 2013 Solvent free clean selective oxidation of alcohols catalyzed by monotransition metal (Co, Mn, Ni)-substituted Keggin-phosphomolybdates using hydrogen peroxide Appl. Catal. A: Gen. 459 59

7. Meenakshi R, Shakeela K, Rani S K and Ranga Rao G 2018 Oxidation of aniline to nitrobenzene catalysed by 1-butyl-3-methyl imidazolium phosphotungstate hybrid material using $m$-chloroperbenzoic acid as an oxidant Catal. Lett. 148246

8. Favette S, Hasenknopf B, Vaissermann J, Gouzerha P and Roux C 2003 Assembly of polyoxometalate into an anisotropic gel Chem. Commun. 2664

9. He P, Xu B, Liu H, He S, Saleem F and Wang X 2013 Polyoxometalate-based supramolecular gel Sci. Rep. 3 https://doi.org/10.1038/srep01833

10. Liu B, Yang J, Yang M, Wang Y, Xia N, Zhang Z, Zheng P, Wang W, Lieberwirth I and Kubel C 2011 Polyoxometalate cluster-contained hybrid gelator and hybrid organogel: a new concept of softenization of polyoxometalate clusters Soft Matter. 72317

11. Tong X and Thangadurai V 2015 Hybrid gel electrolytes derived from keggin-type polyoxometalates and imidazolium-based ionic liquid with enhanced electrochemical stability and fast ionic conductivity $J$. Phys. Chem. C 1197621

12. Huang T, Xie Z, Wu Q and Yan W 2016 Reversible phase transformation gel-type ionic liquid compounds based on tungstovanadosilicates J. Alloys Compd. 660 17

13. Pandya V M, Kortz U and Joshi S A, 2015 Encapsulation and stabilization of polyoxometalates in self-assembled supramolecular hydrogels Dalton Trans. 4458

14. Li C, Lu J, Tu F, Chen J and Li Y 2011 Study of the first antibacterial agent pipemidic acid modifying Keggin polyoxometalate Inorg. Chem. Commun. 14 1192

15. Dong Z, Tan R, Cao J, Yang Y, Kong C, Du J, Zhu S, Zhang Y, Lu J, Huang B and Liu S 2011 Discovery of polyoxometalate-based HDAC inhibitors with profound anticancer activity in vitro and in vivo Eur. J. Med. Chem. 462477

16. Inoue M, Segawa K, Matsunaga S, Matsumoto N, Oda M and Yamase T 2005 Antibacterial activity of highly negative charged polyoxotungstates, $\mathrm{K}_{27}\left[\mathrm{KAs}_{4} \mathrm{~W}_{40} \mathrm{O}_{140}\right]$ and $\mathrm{K}_{18}\left[\mathrm{KSb}_{9} \mathrm{~W}_{21} \mathrm{O}_{86}\right]$, and Keggin-structural polyoxotungstates against Helicobacter pylori J. Inorg. Biochem. 991023

17. Wang Y, Li W and Wu L 2009 Organic-inorganic hybrid supramolecular gels of surfactant-encapsulated polyoxometalates Langmuir 2513194

18. Piepenbrock M M, Lloyd G O, Clarke N and Steed J W 2010 Metal and anion binding supramolecular gels Chem. Rev. 1101960

19. She S, Bian S, Huo R, Chen K, Huang Z, Zhang J, Hao J and Wei Y 2016 Degradable organically-derivatized polyoxometalate with enhanced activity against glioblastoma cell line Sci. Rep. 6 https://doi.org/10.1038/ srep33529 
20. Geisberger G, Paulus S, Carraro M, Bonchio M and Patzke G R 2011 Synthesis, characterisation and cytotoxicity of polyoxometalate/ carboxymethyl chitosan nanocomposites Chem. Eur. J. 174619

21. Geisberger G, Paulus S, Gyenge E B, Maake C and Patzke G R 2011 Targeted delivery of polyoxometalate nanocomposites Small. 72808

22. Menon D, Thomas R T, Narayanan S, Maya S, Jayakumar R, Hussain F, Lakshmanan V and Nair S V 2011 A novel chitosan/polyoxometalate nano-complex for anticancer applications Carbohydr. Polym. 84887

23. Matteis L, Mitchell S G and de la Fuente J M 2014 Supramolecular antimicrobial capsules assembled from polyoxometalates and chitosan J. Mater. Chem. B 27114

24. Feng Y, Han Z, Peng J, Lu J, Xue B, Li L, Ma H and Wang E 2006 Chitosan-polyoxometalate nanocomposites: synthesis, characterization and application as antimicrobial agents Mater. Lett. 601588

25. Rejinold N S, Muthunarayanan M, Divyarani V V, Sreerekha P R, Chennazhi K P, Nair S V, Tamura H and Jayakumar R 2011 Curcumin-loaded biocompatible thermoresponsive polymeric nanoparticles for cancer drug delivery J. Colloid Interface Sci. 36039

26. Rejinold N S, Thomas R G, Muthiah M, Chennazhi K P, Manzoor K, Park I, Jeong Y Y and Jayakumar R 2015 Anti-cancer, pharmacokinetics and tumor localization studies of $\mathrm{pH}-, \mathrm{RF}$ - and thermo-responsive nanoparticles Int. J. Biol. Macromol. 74249

27. Neitzel M L, Aubele D L, Marugg J L, Jagodzinski J J, Konradi A W, Pleiss M A, Szoke B, Zmolek W, Goldbach E, Quinn K P, Sauer J, Brigham E F, Wallace W, Bova M P, Hemphill S and Basi G 2011 Amino-caprolactam csecretase inhibitors showing potential for the treatment of Alzheimer's disease Bioorg. Med. Chem. Lett. 213715

28. Shakeela K, Sinduri V L and Ranga Rao G 2017 Hydrophobic supramolecular assemblies of Keggin anions with lactam-lactim cationic tautomers Polyhedron 13743

29. Kobayashi D, Ouchi Y, Sadakane M, Unoura K and Nabika H 2017 Structural Dependence of the Effects of Polyoxometalates on Liposome Collapse Activity Chem. Lett. 46533

30. Vukovic J S, Babic M M, Antic K M, Filipovic J M, Stojanovic S T, Najman S J and Tomic S L 2016 In vitro cytotoxicity assessment of intelligent acrylate based hydrogels with incorporated copper in wound management Mater. Chem. Phys. 175158

31. Feng Y, Han Z, Peng J, Lu J, Xue B, Li L, Ma H and Wang E 2006 Fabrication and characterization of multilayer films based on Keggin-type polyoxometalate and chitosan Mater. Lett. 601588 